\title{
CIVIL PREPARATION OF THE BATTLESPACE - NECESSITY IN THE IRREGULAR OR HYBRID WARFARE
}

\author{
Aurelian RAṬIU \\ "Nicolae Bălcescu" Land Forces Academy of Sibiu, Romania \\ aurelian_ratiu@yahoo.com
}

\begin{abstract}
The lessons learned from the most recent conflicts or theatres of operations in Iraq, Afghanistan, Ukraine, or Syria prove that the Intelligence Preparation of the Battlefield (IPB) process is no longer sufficient. Why? Because in the irregular and hybrid conflicts the centre of gravity is represented by the civilian population, which requires precise understanding of the operational environment, including aspects about the local communities, and profound knowledge of the people, their social structures, their culture, their customs, and their way of thinking and reacting to certain internal and external stimuli. In such an operational environment, protecting the civilian population becomes the main mission of the armed forces.

Consequently, we present the most important stages through which the Civil Preparation of the Battlespace (CPB) can be accomplished.
\end{abstract}

Keywords: operational environment, civilian population, civilian environment, civil preparation of the battlespace.

\section{Introduction}

The current operational environment is the framework for the manifestation of hybrid threats, assuming the complex and combined configuration of the multitude of actors, means, actions and effects that converge in concert and, most of the time, secretly, towards the fulfillment of political, economic, or military goals. It should allow all kinds of military and non-military actions, emphasizing, thus, not only the need to focus the actions on controlling and influencing the local civilian population, but also the imperative of integrating all the capabilities (forces) into joint actions.

In classic/traditional warfare, the centre of gravity should be identified in the enemy's troops.

Irregular Warfare focuses on influencing or controlling the civilian population, not controlling the forces of an opponent or its territory. The purpose is to undermine the authority of a government, non-state organizations or groups or an ideology by influencing the population. In the IW, the population represents the center of gravity for both parties involved in the conflict.

A careful analysis of the considerations regarding the civilian population is essential to accomplish the objectives in conflict or in the theater of military operations, but especially to achieve long-term success.

For an accurate analysis of the civilian population and the Intelligence Preparation of the Battlefield process, including the human terrain perspective, a few stages must be taken into consideration.

1. Defining the civilian environment where the operations take place

This first stage involves collecting, classifying, organizing and registering the 
information and the results of the intelligence activities regarding the civilian population and the local communities.

In the operations of the latest hybrid conflicts a series of methods, mechanisms, methodologies were introduced in the decision making process, analyzing, extensively:

- On the one hand, specific aspects regarding the local population, such as: ASCOPE (Areas, Structures, Capabilities, Organizations, People, Events)[1], these fields represent, in fact, the meaning of the acronym ASCOPE;

- On the other hand, the socio-cultural factors that might influence local population action, through PMESII-PT (Political, Military, Economic, Social, Infrastructure, Information, Physical Environment, and Time)[2].

A means of analyzing and understanding this important factor of the hybrid conflict, the local population, is ASCOPE methodology.

A) The first ASCOPE field - Areas, refers to the inhabited areas (towns, communes, villages, refugee camps, etc.) where different ethnic groups live and the physical territory (the area of responsibility and the area of influence in an area of operations).

B) The existing structures elements can have a significant role in the development of the military and the civilian-military operations[3]:

- Harbors, airports, railways, roads, bridges, power plants, dams, radio or TV relays are important infrastructure assets that can be converted into military objectives or can be used for military purposes;

- Elements such as churches, mosques, libraries and hospitals are objectives that must be protected, inclusive ballistic protection[4]:, as they are of interest to the community.

Infrastructure analysis involves determining the benefits of location, functionality and capability of such elements in the conduct of operations. When commanders decide on the use of an infrastructure element, they must analyze the ratio between the gained military advantage compared to the extent of the damage.

C) Capabilities refer to the ability of government authorities to provide citizens administrative, civil protection, emergency assistance, strict needs (food, water), etc. services.

Capabilities also refer to the resources and services provided by the host nation, which can be contracted in support of military operations, such as interpreters, cleaning services, providing materials and construction equipment. The commanders and the staff need to analyze capabilities from the perspective of saving, maintaining and improving the quality of life.

This field describes infrastructure variables, with focus on the following elements[5]: drinking water supply network, electricity/ gas supply network, educational facilities network, medical facilities network, sanitation system, facilities network specific to police and civil protection, sewerage network and others.

D) Organizations are represented by affiliated/non-affiliated institutions/groups that carry out activities within the area of operation, influencing and interacting with the population, with the military units and with each other.

Some organizations may come from outside the operations area, such as multinational corporations, UN agencies, government agencies of coalition states, international organizations.

The requirements for this area, organizations, are to have a hierarchical structure and well-defined goals, to carry out pre-established activities, to have headquarters or meeting places as well as logistic and financial support.

E) People - this category includes the civilian population located in the area of operations or in the area of interest.

In this field, the following questions should be answered: How many people live in the area of operations? Which are the 
demographic aspects? What is the impact of the population (the psychological, political, economic, illicit component) on operations? In the analysis of individuals, the most important aspects are: historical, cultural, ethnic, linguistic, economic and humanitarian[6].

Other elements related to the identification of formal and informal means of communication/transmission of information, visual signals (video/ TV images, posters, graffiti), audio signals (radio shows, speeches) are also relevant. People who speak on behalf of the community - local leaders, religious leaders, trade union leaders must be included in the analysis matrix of this variable[7].

F) The conduct of military operations, the activities of the organizations in the area of interest and of the population are influenced by the public or private events [8]. These are routine, cyclical or spontaneous activities, such as: national or religious holidays, cultural events, seasonal fairs, election campaigns, economic events, or civil disturbances.

The analysis of the civilian population is carried out by making the ASCOPE matrix and its graphical materialization on a map or overlay. The multinational forces, host nation security forces and local government officials contribute to this materialization by providing relevant data on the local population.

Following the classification of information on local communities, the operational variables PMESII can be used:

1. The Political variable describes the distribution of responsibility and power at all levels of government to include political power structures (formal and informal);

2. The Military variable includes all existing military capabilities: the military forces of the host state, police forces, insurgent forces, local militias;

3. The Economic variable consists in general economic aspects in the area of operations (energy, raw materials, labor distribution, income, accessibility to food, goods and services, illicit markets);

4. The Social variable describes the social structures in the operational environment (the population whose members have the same political authority, occupy a common territory, have a common culture and share the same sense of identity);

5. The Information variable analyses both the access to and the collection, use, handling and distribution of information and knowledge by local communities, through media and the civilian and military educational systems;

6. The infrastructure variable includes facilities, services and installations that are essential and necessary for a community to function.

The final product of the first stage is to integrate all aspects regarding the civilian population, compiling the ASCOPE and PMESII tools.

\section{Human terrain analysis}

In the second stage, the focus is on analysing the information collected during the first stage. The analysis considers the operational variables, the operational culture and the dynamics of stability and/or instability. The final products include: the matrix of identified civil factors (their relevance), the cultural-operational panoply, and the analysis of the stability/instability factors.

At this stage, the initial effort is to carefully consider the considerations regarding civilians, by using the PMESII operational variables to determine the factors relevant to coalition operations, and to help understand the stability/instability dynamics in a given area, in the following way[9]:

a) The political variable / areas: What is the political situation in the area of operations? What are the political limits? What is important from a political perspective?

b) The military variable / areas: What military capabilities are there in the area of operations? What are the limits of the military structures? What is important from 
a military perspective?

c) The economic variable / areas: What are the most important economic activities in the area of operations?

d) The social variable / areas: What is the social climate in the area of operations? What are the key factors affecting operations in the area of operations - radical ethnic enclaves, high crime areas, etc.;

e) The information variable / areas: How is information collected and / or disseminated in the area of operations? What are the essential requirements regarding the information in the area of operations?

F) The infrastructure variable / areas: What are and where are the key infrastructure elements in the area of operations?

To have the best representation of the most relevant civilian considerations, it is necessary to compile the information in a matrix of civilian factors and their relevance from the perspective of ASCOPE/PMESII - Areas.

Such an analysis should be done for each ASCOPE component (as described above in the Areas domain) taking into account the mission of the force, the intent and the concept of operations.

In addition to the matrix of civilian factors, both the operational culture and the dynamics of stability/instability are examined in combination with the ASCOPE/PMESII methodology. This is done to determine the relevant factors from two different perspectives, which are of great importance to arrive at an in-depth understanding of the human terrain.

The operational culture is also analyzed from the perspective of five dimensions that can influence the conduct and the attitude of the civilian population, on the one hand, and the operational behavior of the insurgent groups, on the other.

These dimensions of the operational culture involve: physical environment (geography), economic culture, social structures, political structures and cultural beliefs/symbols[10]. Knowing the culture of the target group (the local population in an areal) provides the military a proper framework for planning and conducting coherent operations, achieving a strict control of the proportionality between the assigned tasks, the carried out actions and the behavior of the local population.

The dynamics of stability/instability. ASCOPE/PMESII analysis is a flexible tool that can be used to provide a clearer picture of the human field in an area of operations.

Understanding the stability/ instability could include identifying the grievances (instability) and the resilience level (stability) of the local population, deducting and anticipating key factors and events that could affect the stability of an area of operations. Such key factors can be: individuals, groups, infrastructure elements, socio-cultural values/beliefs that could have a significant influence on mission accomplishment, and should be considered in the planning and conduct of operations.

\section{Determining a model of the civilian environment where the operations take place}

A model of the civilian environment in the area of operations should describe the complexity of the system of the factors that have a major impact on the mission. Such a model includes:

- A detailed analysis of what is meant by the civilian environment specific to the area of operations (the elements from the previous stages are used);

- A list of major impact factors deducted by analytical methods;

- The graphic materialization of major impact factors on a map or overlay.

Regarding the identification of the key factors that have a major impact, answering questions like below could be useful[11]:

- What are the sources and nature of factors that may affect the operations of the governmental/coalition forces?

- How do factors influence the operations of the governmental/coalition forces?

- How and how quickly is the effect of 
factors seen, and what is the impact on operations?

- What is the magnitude of the effect of some factors (number of people, group size, location)?

If the answers to the above questions indicate that the factors could have a significant impact on operations, then they should be included in the civilian model.

This model should also present three aspects:

- Motivation and goals;

- The capabilities and the means of the "key factors";

- The impact that these factors may have on operations/the achievement of the objectives.

\section{Determining civilian population actions}

At this stage, the activity focuses on the use of previous information, analyzes and matrices to predict, as accurately as possible, the actions of the civilian population; on the one hand, those supporting the actions of the governmental forces, and on the other hand those that support the insurgent groups. These elements provide a realistic image of what human terrain means, allowing planners to integrate the efforts of all involved forces for a successful accomplishment of any the mission: stabilizing the conflict situation and supporting the civilian population.

In order to determine the actions of the civilian population that can influence or modify the approach to the mission, one could take into consideration aspects such as:

- Historical patterns of the population;

- Conditions/desiderata that the population is trying to reach;

- Work agenda and objectives of the key factors in the operation area.

The outcome of this final stage is represented by the description and the graphic materialization of the most important possible actions of the civilian population: those that a benefit for the governmental forces and those that are in their disadvantage.

\section{Conclusions}

To conclude, we can state that by being aware of the importance of the human terrain and by using these tools and stages, the in-depth knowledge of the civilian population is achieved, facilitating cooperation, harmonization of activities, information exchange, planning and management of operations to reach the center of gravity: the control of the civilian population.

Civil Preparation of the Battlespace complements the database with regular information from the field, outlining the socio-cultural profile of the local population. This analysis is a scientific one, much deeper and more accurate than the assumptions formulated by the forces in the field.

Integrating the socio-cultural profile in the decision-making process is a very important factor for the conduct of the operations and the achievement of the expected effects.

Estimation of the effects caused by cultural deployment in the operational environment can be done with much accuracy. Also, the contact between individuals from different cultures, the so-called "cultural shock", can be diminished. Evaluating the effects of the military action and recommending some adjustments to avoid breaking relations as a result of inevitable cultural clashes is a process at which $\mathrm{CPB}$ brings an important contribution.

Knowing the culture of the local population in a (hybrid or irregular) conflict area provides the military a proper framework for planning, decision-making and conducting coherent operations, carrying out strict control of the proportionality between the assigned tasks, the carried out actions and the behavior of the local population. 


\section{References}

[1] Department of the Army, FM 3-0 Operation, February, 2008, chapter 6, p. 10.

[2] Ibid, chapter 1, p. 5.

[3] United States Marine Corps Marine Corps, Civil-Military Operations School, Student Outline. Civil Preparation of the Battlespace (CPB), Virginia, USA, 2015, pp. 3-4, http://www.trngcmd.marines.mil/Portals/207/Docs/wtbn/MCCMOS/0530\%20Civil\%20 Preparation\%20of\%20the\%20Battlespace\%20(CPB).pdf, accessed at 10.03.2016.

[4] Ilie Florin, Protecție balistică, „Nicolae Bălcescu” Publishing House, Sibiu, 2015, p.34.

[5] Laviniu Bojor, Conflictul iregular - conflict militar caracteristic primelor decenii ale secolului al XXI-lea, „Nicolae Bălcescu” Publishing House, Sibiu, 2016, pp. 120.

[6] Joint Chiefs of Staff, Joint Publication 3-24 - Counterinsurgency, SUA, November 2013, chapter IV, p. 13, on http://www.dtic.mil/doctrine/new_pubs/jp3_24.pdf, accessed at 10.03.2016.

[7] Department of the Army, FM 3-05.401 - Civil Affairs Tactics, Techniques, and Procedures, Washington DC, USA, 2007, chapter 3, p. 25.

[8] Ibid, chapter 3, p. 25.

[9] United States Marine Corps Marine Corps, Civil-Military Operations School, Op.cit., p. 7.

[10] US Army Combined Arms Center, Center for Army Lessons Learned, Handbook Commander's Guide. Employing a Human Terrain Team in Operation Enduring Freedom and Operation Iraqi Freedom. Tactics, Techniques, and Procedures, Leavenworth, United States of America, March 2009, pp. 16-17, http://www.globalsecurity.org/military/library/report/call/call_09-21.pdf, accessed at 08.02.20117.

[11] United States Marine Corps Marine Corps, Civil-Military Operations School, Op.cit., pp. 14-15. 